\title{
La influencia visual de IBM en las primeras cabeceras de revistas españolas de informática para usuarios
}

\author{
Carlos JiMÉNEZ NARROS \\ Universidad Nebrija \\ cjimenez@nebrija.es
}

Recibido: $17 / 10 / 2012$

Aceptado: 23/01/2013

\begin{abstract}
Resumen
A comienzos de la década de los ochenta conviven una variada oferta de computadoras -Commodore, Sinclair, Amstrad- pero IBM (International Business Machines) es la marca comercial que consigue ganar la batalla en el mercado de los ordenadores personales compatibles, Personal Computer (PC). El logotipo actual de $I B M$ fue diseñado por Paul Rand a mediados de los años cincuenta y tras la proyección internacional de esta empresa, su aspecto visual provoca una fuerte influencia y comienza a ser imitado por empresas, instituciones, tiendas de informática, electrónica y más en concreto por el sector editorial de revistas especializadas en informática para usuarios. Esta investigación nos retrotrae a las primeras cabeceras españolas especializadas en informática para usuarios y en especial aquellas en las que se evidencia dicha influencia. Este análisis forma parte de una investigación más amplia titulada: Evolución del diseño de revistas de informática para usuarios avanzados en España.
\end{abstract}

Palabras clave: cabeceras de revistas, revistas de informática, identidad de marca, IBM, logotipo.

\section{The Visual Impact of IBM in the Earliest Spanish Magazines Headers in Computing for Final Users}

\begin{abstract}
In the early eighties coexist a wide range of computers -Commodore, Sinclair, Amstrad-but IBM (International Business Machines) is the brand that wins the battle in the market for personal computers, compatible Personal Computer (PC). The current IBM logo was designed by Paul Rand in the mid-fifties and after the international projection of this company, its visual appearance causes a strong influence and begins to be imitated by companies, institutions, computer stores, electronics shops and more specifically for the publishing of magazines especialized in computing for final users. This research brings us back to the first Spanish headers specialized in computer users and especially for those in which this influence is evident. This analysis is part of a large research titled: Design evolution of computer magazines for advanced users in Spain. This research brings us back to the earliest Spanish headers specialized in computing for users and especially for those in which this influence is evident. This analysis is part of a large research titled: Design evolution of computer magazines for advanced users in Spain.
\end{abstract}

Keywords: headers magazines, computer magazines, brand identity, $I B M, \log 0$

\section{Referencia normalizada}

JIMÉNEZ NARROS, Carlos (2013): "La influencia visual de IBM en las primeras cabeceras de revistas españolas de informática para usuarios". Estudios sobre el mensaje periodístico. Vol. 19, Núm. especial abril, págs.: 843-851. Madrid, Servicio de Publicaciones de la Universidad Complutense.

Sumario: 1. Introducción. 2. Metodología. 3. La imagen de marca de IBM; 3.1. Las aportaciones de Paul Rand; 3.2. La influencia visual de IBM en las cabeceras de revistas de informática. 4. Conclusiones. 5. Referencias bibliográficas.

\section{Introducción}

La importancia de las primeras revistas de informática para usuarios, en la década de los ochenta, fue decisiva para difundir la disciplina, en un momento en el que los ma- 
nuales de los fabricantes y la prensa más técnica eran las únicas fuentes de información disponibles para los usuarios. Durante las décadas de los sesenta, setenta y ochenta no podemos obviar el poderoso impacto ejercido por ciertas marcas comerciales de productos informáticos. El ejemplo más emblemático fue sin duda $I B M$, pero hubo otras identidades visuales que también provocaron una fuerte influencia estética en todo el sector de las nuevas tecnologías, hablamos de Altair 8800 y Sinclair.

En el caso de la imagen de marca del microprocesador Altair 8800 utilizaba una tipografía semejante a la Countdown -cuenta atrás-creada en 1965 por el imaginativo diseñador Colin Brignall para Letraset. Este tipo de letra fue uno de sus primeros frutos y gozó de mucha popularidad porque evocaba imágenes de fantasía científica de los años sesenta. También sirvió de inspiración para las cubiertas de publicaciones de ciencia ficción, electrónica, informática y boutiques de moda. Rótulos que proclamaban una modernidad futurista. Countdown es la tipografia utilizada por la cabecera de las publicaciones Mundo Electrónico y Byte.

Si observamos el ejemplo de la marca Sinclair comprobamos que las cabeceras de revistas, -Sinclair ZX Spectrum, Input Sinclair y Sync- con contenidos sobre este mismo tipo de máquinas utilizan la misma tipografía lineal, geométrica y sin remates que la imagen de marca del producto. Muchas veces las propias empresas comerciales eran quienes editaban las publicaciones para poder difundir mejor sus productos tecnológicos entre los usuarios.

De manera más significativa le ocurrió a la imagen visual del $I B M$ sobre todo en algunas de las cabeceras o logotipos de revistas de informática para usuarios. A comienzos de los ochenta existía una variada oferta de computadoras, pero cuando $I B M$ presenta en 1981 el PC se convierte en el primer estándar de la informática personal y su repercusión visual se hace notar exponencialmente en el sector de las publicaciones periódicas.

\section{Metodología}

Para la obtención de los objetivos fijados en esta investigación hemos establecido dos itinerarios. El primordial comprende el análisis visual del logotipo de $I B M$ y de las primeras cabeceras de revistas de informática para usuarios avanzados. El apartado gráfico de esta investigación tiene un peso muy significativo. Algunas imágenes, sobre todo las referidas a las publicaciones especializadas en informática de los primeros años de los ochenta, han sido consultadas en la Biblioteca Nacional. Hemos completado esta recopilación gráfica con un rastreo por Internet, visitando páginas de coleccionistas, y espacios dedicados a editoriales y revistas especializadas en informática.

El segundo itinerario que refuerza y completa al anterior han sido las fuentes secundarias. Con la ayuda de ellas se ha construido el marco teórico sobre el que se articula y desarrolla la investigación. Para ello hemos revisado materiales especializados sobre todo en informática, nuevas tecnologías, usuarios, revistas y diseño. Se han consultado todo tipo de recursos: bases de datos, monografías, diccionarios, guías, hemerografías, actas de control, tesis doctorales, estudios, informes, artículos, ponencias, páginas web, además de las propias revistas especializadas en informática. 


\section{La imagen de marca de IBM}

$I B M$ se funda en 1911 tras la fusión de varias empresas y entonces tomó el nombre de Computing Tabulating Recording Corporation (CTR). Desde 1881 funciona bajo el nombre de Tabulating Machine y es en 1924 cuando adquiere el nombre con el que hoy se la conoce internacionalmente, International Business Machines (IBM).

Tom Watson Jr., presidente y director general de la marca, tenía claro que $I B M$, en estos años, ya era conocida por su servicio y producción, pero le faltaba crear una identidad corporativa completa, es decir un uniforme moderno con el que se pudieran vestir no sólo sus productos, sino también todas sus demás manifestaciones (Lieverse y Nijs, 1991: 106)

Tom Watson se inclinaba más por la estética y filosofía de los creativos europeos que la de los americanos y por ello reclutó a un equipo de diseñadores acordes con este pensamiento.

Un reducido número de personas se encargaron de gestionar el diseño y la estética de esta marca comercial: Elliot Noyes (diseño industrial) Charles Eames (exposiciones y films) y Paul Rand (aspectos gráficos). Schmitt y Simonson (1998: 77-78) indican que este sistema de gestión tan personalizado sirvió para que $I B M$ se estableciera positivamente como Big Blue -Gigante Azul, apelativo con el que se le conoce en Estados Unidos-, un impresionante modelo de empresa tecnológica contemporánea. Desde sus comienzos el color azul está íntimamente ligado a su identidad visual, hablándose incluso de "azul IBM". El diseño de su imagen de marca tan potente hace que hoy día sea reconocida por todos como una empresa multinacional de referencia.

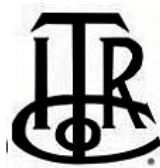

1888

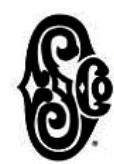

1891

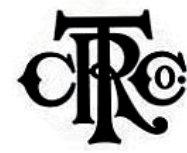

1911

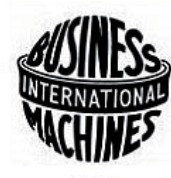

1924

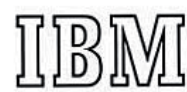

1947

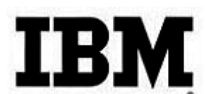

1956

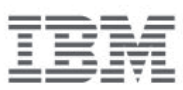

1972

Imagen 1. Evolución del logotipo de IBM

Fuente: www.abadiadigital.com

Eliot Noyes estudió arquitectura y diseño industrial. Fue asesor de diseño, entre otros, para Westinghouse y Pan American Móvil (son obra suya las bombas redondas de gasolina que todavía se usan en todas partes). Su tarea en $I B M$ consistió en supervisar el diseño del producto y la arquitectura interior, $\mathrm{y}$, como consecuencia de su trabajo en 1956 se le nombró director corporativo de diseño. Eliot Noyes y Paul Rand comienzan a trabajan en sintonía con los principios del buen diseño europeo. Les atraía sobre todo el trabajo de Marcello Nizzoli, que era el diseñador de la identidad corporativa de Olivetti (1956). Fue una de las primeras multinacionales que estableció un estilo coordinado para todas las oficinas en el extranjero, con IBM como principal competidor. 
El símbolo de Olivetti (Baltanás, 2004: 46) describe un recorrido prefijado, rectilíneo y geométrico, para finalizar en un logotipo con letras de caja baja y acabados redondeados. La precisión y la arista contrastan con la amabilidad curvilínea para componer así una metáfora que identifique la personalidad de los productos diseñados y, por extensión, de la institución: metodología y creatividad, control e imaginación, rigor y genio. En suma, consigue atender a los aspectos funcionales y estéticos y lograr una dual armonía de contrarios: la unión en la multiplicidad.

Para $I B M$ un diseño uniforme, canalizado hacia un estilo de empresa distinto, tenía básicamente el mérito de ser práctico: debía ser reconocible universalmente y representar el alto nivel social en que la firma funcionaba (Lieverse y Nijs, 1991: 107).

Esta ética de empresa está basada en principios de disciplina que se han practicado durante siglos en otros lugares, como las fuerzas armadas. Esta actitud fue la que tomó Tom Watson Jr. en $I B M$.

Nunca tendrás éxito en ningún cometido si no estás convencido de que eres el mejor del mundo. Tienes que poner tu alma en el negocio y el negocio dentro de tu alma. (Lieverse y Nijs, 1991: 109)

$I B M$ contempla que el diseño de sus productos debe tener un atractivo universal, elevando su valor de mercado; particularmente desde que opera en el mercado internacional. No sólo sus productos deben proyectar su identidad en todo el mundo, sino que sus oficinas también deben emitir ese mismo aura multinacional. Es uno de los mejores programas de identidad y se ha convertido, por ende, en un modelo destacado por su enfoque pragmático y efectivo.

\subsection{Las aportaciones de Paul Rand}

Las ideas de Paul Rand encajaban claramente con la mentalidad de $I B M$. Su filosofía era que "el buen diseño en espíritu es la simple honestidad". El artista László Moholy-Nagy caracterizó a Rand como: "Es un idealista y un realista, utilizando al mismo tiempo el lenguaje del poeta y del hombre de negocios. Siempre piensa en términos de necesidad y de función. Es capaz de analizar sus problemas, pero su fantasía no tiene límites".

Paul Rand (Nueva York 1914 - Norwalk 1996) estudió arte en las tradicionales escuelas neoyorquinas de Pratt Institute, Parsons School of Design y Art Students League, donde tuvo de profesor a George Grosz. Empezó su carrera como tipógrafo para la revista Esquire. Entre 1941 y 1954 trabajó para la agencia publicitaria de Bill Bernbach y, luego, empezó a trabajar por su cuenta diseñando programas de imagen corporativa para la poderosa industria de electrodomésticos Westinghouse, para $A B C$ y United Parcel Service, convirtiéndose en el diseñador de referencia de Estados Unidos. También fue el responsable de la imagen de $N e X T$. Fue profesor y autor, entre otros del libro Thoughts in desing (1947). Tenía muy clara la idea de su trabajo como se manifiesta en la primera página del libro: "El diseño gráfico - que cumple con la estética, las leyes de la forma y las exigencias del espacio bidimensional, que se expresa con pictogramas, tipografías y geometrías, con abstracciones, transformaciones, traslaciones, rotaciones, extensiones, repeticiones, reflexiones, agrupaciones y reagrupaciones- no es bueno si es irrelevante", o "El diseño gráfico -que evoca la simetría de 
Vitruvio, la dinámica de Hambidge y la asimetría de Mondrian; que une lo bello y lo útil; que se genera con la intuición y el ordenador, según obedezca a la invención o coordinación- no es buena si no está al servicio de la comunicación".

Este diseñador no sólo redefinió el antiguo logotipo de IBM, sino que desarrolló un tipo de letra de la casa. Jesús García Yruela (2003: 8) al referirse a las letras mecanas, grupo en el que se clasifica la tipografía de IBM, señala que el ensamblamiento de líneas, todas de la misma naturaleza racional y funcional, buscan como único objetivo la utilidad y la eficacia.

Se inspiró en la tipografía City Medium creada en 1930 por el diseñador alemán Georg Trump para la fundición de tipos de Berthold. Como señala Solomon (1988: 194) es un tipo egipcio de perfil rectangular, las letras habitualmente redondas se han transformado en cuadradas.

\section{ABCDEFGHIJKLMNOPQ RSTUVWXYZ abcdefghijklmnopq rstuvwxyz $1234567890 \& \$$ «€}

Imagen 2. City Medium es la tipografía original sobre la que se trabajó.

La tipografía City es una estilizada interpretación del amor modernista a la geometría. Paul Rand lo que hizo fue sustituir en la City Médium los trazos interiores curvos de las letras por trazos rectos. Decía que: "Las letras puestas en logotipos, marcas, sellos o monogramas poseen una cualidad mágica y facilitan, no sólo su entendimiento, sino también su forma".

Algunas veces es denominado como alfabeto especial, por haber sido poco usado y porque este tipo de letra nunca ha tenido un nombre propio. Su aplicación mundial creó una buena cantidad de complicaciones técnicas y logísticas. Por ello, en su guía de diseño de 1961, el propio Rand advertía: "Usadlo de forma restringida y no lo uséis para títulos y trabajos de diseño general, a menos que sea absolutamente esencial".

El logotipo de $I B M$ tiene una cara positiva y una cara negativa, una modalidad subrayada, una versión de ocho franjas horizontales y otra de trece. Cada una de ellas se utiliza con una función distinta. Las dos mencionadas en último lugar son particularmente llamativas. Sus líneas no sólo mantienen nuestra atención, sino que también sugieren velocidad, eficiencia y seguridad.

Evamy (2008: 195) señala que el eterno logotipo de ocho franjas de $I B M$ llegó por etapas. A mediados de los cincuenta, mientras diseñaba materiales de impresión para la empresa, Rand aligeró el logo de tipos egipcios existentes. Consciente de que un cambio brusco se ganaría la antipatía de la junta directiva de $I B M$, Rand esperó varios años antes de aventurarse a sacar una versión rayada. Finalmente, ganaron la batalla sus connotaciones de seguridad - para evitar la falsificación de documentos firmadosy su habilidad de unir visualmente las pesadas y competitivas letras. 
Las tres letras $(I B M)$ parecen estar unidas, produciendo un efecto fuerte de coherencia. La versión de ocho líneas se usa principalmente en embalaje y material de exhibición, y la de trece, cuando se necesita dar un énfasis más especial al logotipo. Las líneas rectas en un logotipo se vinculan a la tecnología, seriedad, formalidad. Normalmente se apuesta por un logotipo con iniciales cuando la institución comprueba que el nombre es demasiado rígido y opta por utilizar tan sólo las siglas con carácter, distinción y de manera atractiva. Además como señala González Solas (2004 : 167) las letras en los logotipos son tratados plásticamente como imágenes, porque lo importante es la diferenciación e identificación visual, más que ser leídos.

Paul Rand sentía especial predilección por la fuerza y expresión de la tipografía. Uno de sus talentos era buscar entidades visuales en las destaque el equilibrio compositivo y su uniformidad. Su éxito radicó en esforzarse por unir gráficamente las letras. Considera que los logotipos deben ser simples para que resulten estéticos.

Álvarez (1988: 24) al referirse a las marcas poderosas habla de una "escala de personalidad", considerando cinco factores básicos:
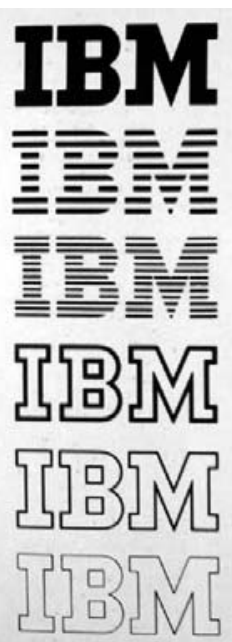

Imagen 3. Distintas versiones del logotipo de IBM sinceridad, excitación, capacidad, sofistificación y rudeza. Cada factor lo vincula a una marca en particular y en el caso de $I B M$ lo asocia a "capacidad", es decir confiable, inteligente, de éxito.

\subsection{La influencia visual de IBM en las cabeceras de revistas de informática} Al principio los directivos de empresas y los profesionales técnicos eran los únicos que demandaban contenidos especializados en informática, pues era una materia solicitada por expertos y técnicos. Con la presentación en sociedad del primer ordenador personal (1981) todos estos conocimientos se expanden a la sociedad de forma masiva. Este progreso tecnológico favorece el nacimiento de los usuarios, una audiencia más numerosa, heterogénea y menos especializada, dando lugar a la aparición de una serie de revistas destinadas a ellos. Muchas de las primeras cabeceras sobre informática comienzan imitando visualmente a la marca $I B M$. La utilización de las famosas rayas horizontales de su logotipo se convierte en un código visual de referencia cuando queremos elaborar mensajes sobre tecnología, futuro y modernidad.

A continuación se muestran imágenes de las cabeceras de revistas brasileñas y americanas, en las que se observa claramente su influencia.
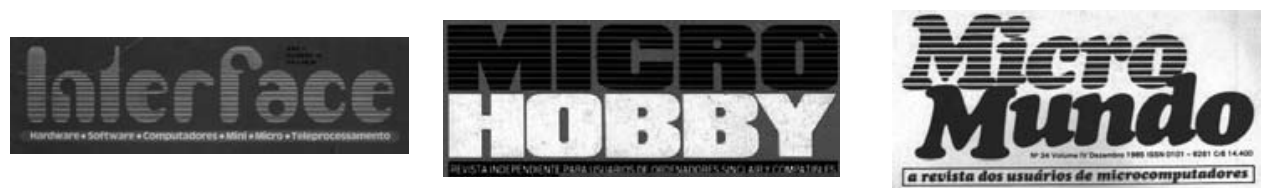

Imagen 4. Revistas brasileñas de informática: Interface, Microhobby y Micromundo donde la imitación del logotipo de IBM es evidente. 


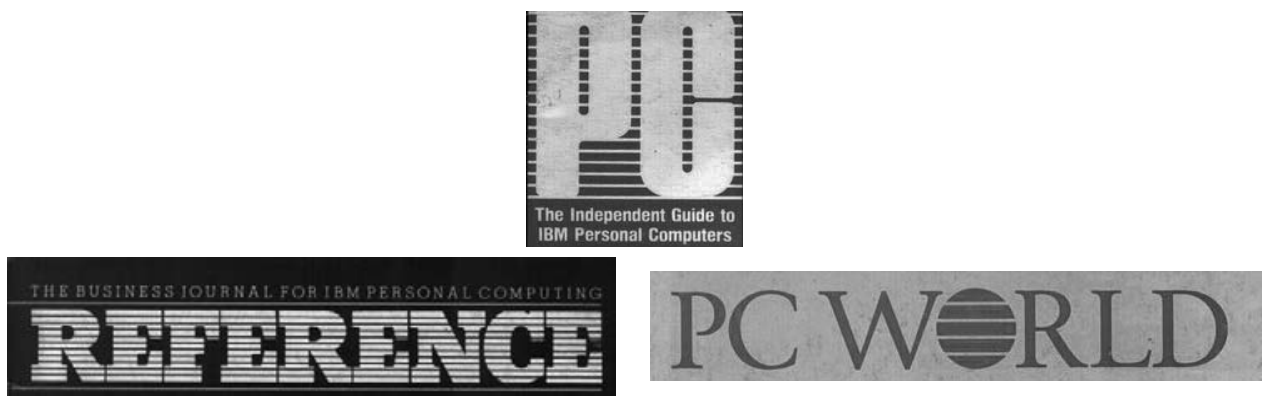

Imagen 5. Revistas americanas en las que la influencia de la imagen de IBM también es palpable: PC (1982), Reference (1983) y PC World (1983).

Para conocer el grado de mimetismo que existe entre la identidad de $I B M$ y las cabeceras de revistas españolas de informática dirigidas a usuarios hemos examinado las primeras publicaciones mensuales referidas a estos contenidos. En profundidad se han revisado los primeros cinco años de la década de los ochenta. Las revistas analizadas son: El Ordenador Personal (1982-1984), Ordenador Actualidad (1982-1983), Panorama de la Informática (1983-1985), Ordenador Popular (1983-1988), Micros/Chip (1983-1992), B Computer (1983-1985), Bip-Bip el Amigo de tu Ordenador (19841986), Tu Micro (1984-1985) y PC World (1985-). Muchas de ellas tienen acuerdos de colaboración con revistas hermanas en otros países: Ordenador Personal (L'Ordinatuer Individual - Francia), El Ordenador Popular (Popular Computing y Byte - Estados Unidos), Micros (Chip - Alemania) y PC World (PC World - Estados Unidos). Los proyectos propiamente españoles son: Ordenador Actualidad, Panorama de la Informática, Bip-Bip el Amigo de tu Ordenador, B Computer y Tu Micro. A partir de 1985 nos hemos acercado sólo a los proyectos gráficos que imitaban la imagen de IBM.

En la década de los ochenta las cabeceras de revistas de informática para usuarios que imitaron su aspecto visual son: Bip-Bip el amigo de tu ordenador, PC Magazine, PC Magazine Actual, PC World, PC Computer y PC Compatible. En algunas ocasiones provocó incluso que revistas como PC Magazine (España) tuviera que aclarar en la página 3 de su editorial del primer número (1985) que el proyecto editorial no tenía nada que ver con el gigante azul, es decir con IBM: "PC Magazine es una revista completamente independiente de Internacional Bussines Machine, de su filial española y de la red de distribuidores autorizados de los ordenadores personales $I B M$

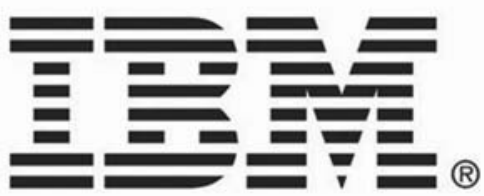

Estudios sobre el Mensaje Periodístico

Vol. 19 Núm. especial abril (2013) 843-851

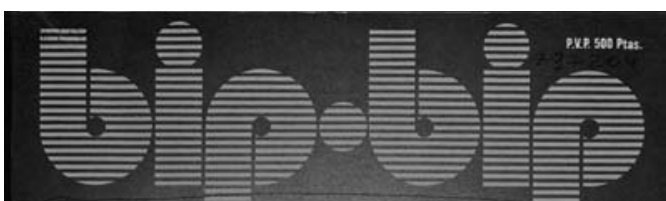

EL AMIGO DE TU ORDENADOR 

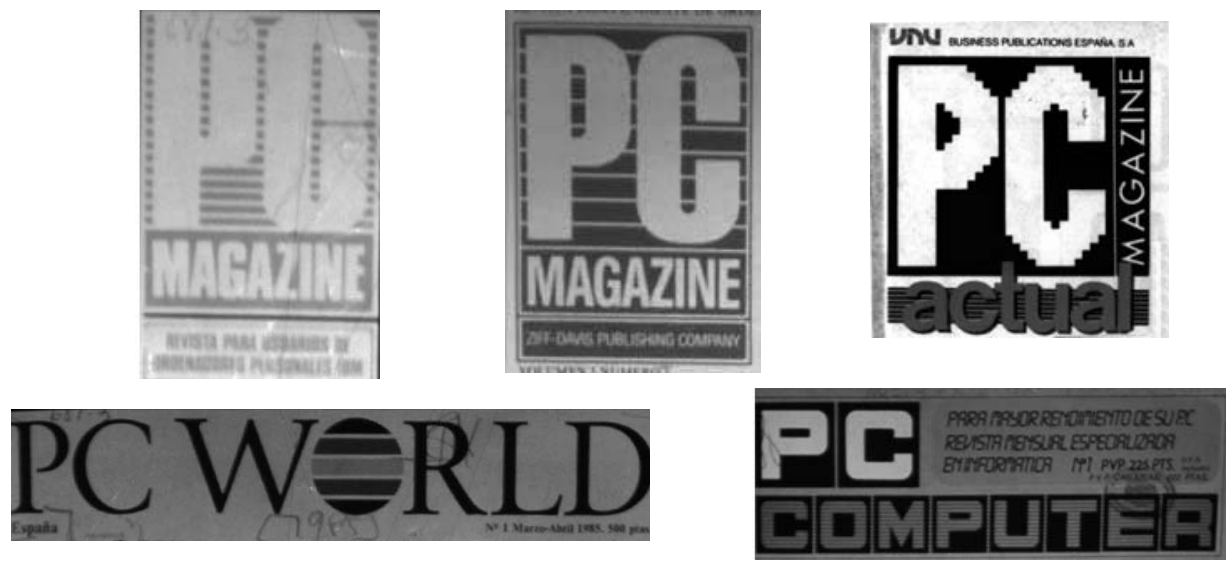

Imagen 6. Cabeceras de revistas españolas de informática de usuarios influenciadas por el logotipo de IBM: Bip-Bip (1984), PC Magazine (1985), PC Magazine (1988), PC Magazine Actual (1988), PC World (1985), PC Computer (1986) y PCompatible (1987). Fuente: Biblioteca Nacional

Anotar que las revistas especializadas en informática dirigidas a usuarios que responden a proyectos editoriales españoles tuvieron una presencia más efímera en el mercado. La vida de estas publicaciones, en el quiosco, no supera los tres años, excepto Tu Micro que se mantiene cinco años, tras los sucesivos cambios de cabecera: Tu Micro Personal (1986) y Revista de Micro Informática Personal (1987-1988). Sin embargo, las publicaciones respaldadas por cabeceras o grupos internacionales persistieron más años en el quiosco.

Alfonso González Quesada y Fernández Sanz (2004: 74) señala que estamos ante un sector editorial muy dinámico en cuanto al número de títulos, pero con un altísimo nivel de transitoriedad de las publicaciones. Las razones son muy diversas: fragilidad empresarial, oferta excesiva y concentrada en un sector de la audiencia muy reducido, o simplemente, obsolescencia de los productos tecnológicos de los cuales se informa.

A finales de los ochenta y principios de los noventa se afianza en el mercado español algunas editoriales extranjeras como IDG y VNU, que darán cierta constancia a varias revistas del sector de las nuevas tecnologías. Dos de estos proyectos mensuales aún siguen vivos en el quiosco, PC Actual y PC World.

\section{Conclusiones}

- El logotipo de $I B M$ y su aspecto visual ha ejercido una fuerte influencia, en la década de los ochenta, en el mercado de las nuevas tecnologías y de manera más concreta, en las cabeceras de publicaciones especializadas en informática.

- Las conocidas rayas horizontales de su logotipo, incorporadas a su diseño en los años setenta, se convirtieron en un código visual oportuno cuando se pretendía sugerir tecnología, futuro y modernidad.

- La versión rayada del logotipo de $I B M$ aporta seguridad, confianza y eficiencia, permitiéndole además, unir plásticamente las tres letras. 
- En la década de los ochenta seis cabeceras españolas de informática dirigidas a usuarios avanzados utilizaron el recurso gráfico de las líneas paralelas. Otras muchas revistas internacionales también lo hicieron.

\section{Bibliografía}

ÁLVAREZ DEL BARCO, Roberto Marcos (2002): “Armonía en imagen, personalidad y carisma de la marca". E-Deusto: conocimiento para ir por delante, $\mathrm{n}^{\circ} .17$, págs. 38-45

BALTANÁS, José (2004): Diseño e historia. Invariantes. Barcelona, Gustavo Gili.

CABELLO, Fernando (1999): El mercado de revistas en España. Barcelona, Ariel.

EVAMY, Michael (2008): Logo. Barcelona, Gustavo Gili.

GARCÍA YRUELA, Jesús (2003): Tecnología de la comunicación e información escrita. Madrid, Síntesis.

GONZÁLEZ SOLAS, Javier (2004): Identidad visual corporativa. Madrid, Síntesis.

GONZÁLEZ QUESADA, Alfonso y FERNÁNDEZ SANZ, Juan José (2002): “La prensa sobre tecnologías de la información en España: Una aproximación a su perfil y evolución histórica". I Congreso de Prensa y Periodismo Especializado. Historia y realidad actual .Guadalajara.

LIEVERSE, Jaap y NIJS, Ronald (1991): “Queremos estar en la cumbre” en ROSELL I MIRALLES, Eugeni: Manual de imagen corporativa. Barcelona, Gustavo Gili.

PC Magazine $\mathrm{n}^{\mathrm{o}}$ 1, enero 1985.

SCHMITT, Bernd H \& SIMONSON, Alex (1998): Marketing y estética. La gestión estratégica de la marca, la identidad y la imagen. Bilbao, Deusto, pp. 77-78.

SOLOMON, Martin (1988): El arte de la tipografía. Madrid, Tellus.

\section{$\overline{\text { Carlos JIMÉNEZ NARROS }}$}

Universidad Nebrija

Facultad de Ciencias de la Comunicación

Coordinador Académico Grado en Periodismo

cjimenez@nebrija.es 